\title{
Desempenho e histomorfometria intestinal de frangos de corte de 1 a 21 dias de idade recebendo melhoradores de crescimento
}

\author{
Lidiana de Siqueira Nunes Ramos ${ }^{1}$, João Batista Lopes ${ }^{2}$, Silvana Maria Medeiros de Sousa \\ Silva ${ }^{3}$, Francisco Eduardo Soares Silva ${ }^{4}$, Mabell Nery Ribeiro ${ }^{4}$ \\ 1 Instituto Federal de Educação, Ciência e Tecnologia do Piauí, Rua Deputado João Carvalho, 4886 - Morada do Sol, Teresina, PI. \\ 2 Departamento de Zootecnia, Centro de Ciências Agrárias Universidade Federal do Piauí. \\ ${ }^{3}$ Departamento de Clínica e Cirurgia Veterinária, Centro de Ciências Agrárias da Universidade Federal do Piauí. \\ ${ }^{4}$ Curso de graduação em Medicina Veterinária e Zootecnia.
}

RESUMO - Esta pesquisa foi desenvolvida para avaliar o desempenho produtivo e a histomorfometria dos segmentos do intestino delgado em frangos de corte no período de 1 a 21 dias de idade alimentados com dietas contendo diferentes aditivos melhoradores de crescimento: ração controle (sem melhorador de crescimento); ração controle + antibióticos (colistina e bacitracina de zinco); ração controle + probiótico; ração controle + prebiótico; ração controle + probiótico + prebiótico. As aves foram distribuídas em delineamento em blocos casualizados, com cinco tratamentos e quatro repetições. Foram avaliadas as variáveis de desempenho, consumo de ração, ganho de peso e conversão alimentar e as características morfométricas, altura, perímetro e profundidade de vilos, dos segmentos do intestino delgado no período de 1 a 21 dias de idade. O desempenho das aves e as características morfométricas dos segmentos dos intestino não apresentaram diferença entre os grupos. $\mathrm{O}$ uso de probiótico, prebiótico, probiótico + prebiótico e antibiótico em rações para frangos de corte no período de 1 a 21 dias de idade em condições de baixo desafio sanitário não interfere no desempenho e nas características histomorfométricas dos segmentos do intestino delgado.

Palavras-chave: antibióticos, prebióticos, probióticos, simbióticos

\section{Performance and intestinal histomorphometry of broiler chickens at 1 to 21 days of age fed growth promoters}

\begin{abstract}
The objective of this work was to evaluate the performance and intestinal histomorphometry of small intestine segments in broiler chickens in 1 to 21 -day of age period, fed diets with different growth promoter additives: control diet (without growth promoter); control diet + antibiotic (colistin and zinc bacitracin); control diet + probiotic (Protexin); control diet + prebiotic (Bio moss); control diet + probiotic + prebiotic. The birds were distributed in a random block design, with five treatments and four replications. It was evaluated variables of performance, feed intake, weight gain and feed conversion and the morphometric characteristics, height, circumference and depth of the villus of small intestine segments in 1 to 21-day of age period. Performance and morphometric traits of small intestine did not present differences among groups. The use of probiotic, prebiotic, probiotic + prebiotic and antibiotic in diets for broiler chickens in 1 to 21-day of age period, in conditions of low health challenge, does not interfere in the performance and in the histomorphometric characteristics of the segments of the small intestine.
\end{abstract}

Key Words: antibiotic, prebiotic, probiotic, symbiotic

\section{Introdução}

O sistema intensivo de produção de frangos de corte, mesmo com uso de alto padrão tecnológico, não assegura que o ambiente de criação das aves esteja livre de patógenos. Quando presentes nas granjas, os patógenos prejudicam a eficiência de aproveitamento dos nutrientes das rações por esses animais, em decorrência do possível surgimento de desordens entéricas. Neste contexto, na cadeia produtiva de frangos de corte, parte dos problemas sanitários tem sido reduzida com o uso dos aditivos zootécnicos, à base de antibióticos.

A utilização dos antibióticos melhoradores de desempenho, pertencentes ao mesmo grupo de drogas empregadas em terapêutica, determinou o aparecimento de formas bacterianas resistentes e prejudiciais à saúde e à terapia animal e humana (Edens, 2003). O aparecimento de cepas resistentes despertou atenção de pesquisadores, 
grupos ativistas e autoridades governamentais envolvidas com a saúde pública, culminando no banimento do uso de antibióticos como melhoradores de crescimento na indústria de alimentação de aves (Halphide, 2003).

Segundo a ABEF (2009), o Brasil destacou-se no período entre 1999 e 2007 como o terceiro maior produtor mundial de carne de frango. Em exportação, atualmente ocupa o primeiro lugar, fato marcante para os produtores, que precisam estar preparados para atender às exigências de exportação. Assim, novas tecnologias são demandadas com a perspectiva, em curto prazo, de substituição dos antibióticos por aditivos alternativos sem que a produtividade avícola e a competitividade no mercado sejam afetadas.

No âmbito mundial, vem despontando os probióticos e prebióticos, que são produtos inovadores, não-tóxicos e que não induzem resistência bacteriana em seres humanos. Segundo Loddi et al. (2000), é possível que os probióticos sejam utilizados em substituição aos antibióticos, pois constituem suplemento aditivo de ração, composto por agente microbiano vivo, não-patogênico, que atua beneficamente no hospedeiro melhorando o equilíbrio microbiano do intestino.

Os prebióticos são definidos como ingredientes nutricionais não digeridos por enzimas, sais e ácidos produzidos pelo organismo animal, sendo, seletivamente, fermentados pelos microrganismos do trato gastrintestinal constituindo o "alimento" das bactérias probióticas (Shane, 2001).

Mais recentemente, passou-se a adotar a terminologia de simbióticos à associação de probióticos e prebióticos. Segundo Araújo et al. (2007), a interação entre o probiótico e o prebiótico in vivo pode ser favorecida por uma adaptação do probiótico ao substrato prebiótico, o que, em alguns casos, pode resultar em vantagem competitiva para o probiótico, se consumido juntamente com o prebiótico.

Esta pesquisa foi conduzida para avaliar o desempenho e histomorfometria dos segmentos do intestino delgado em frangos de corte no período de 1 a 21 dias de idade alimentados com dietas contendo diferentes melhoradores de crescimento, como antibióticos, probiótico, prebiótico e probiótico + prebiótico.

\section{Material e Métodos}

Foram utilizados, no período experimental de 1 a 21 dias de idade, 480 pintos da linhagem Ross selecionados pelo peso, sendo 240 machos e 240 fêmeas. As aves foram alojadas em 20 boxes, com área de $3,00 \mathrm{~m}^{2}$ cada, distribuídos em galpão de alvenaria, coberto com telhas de barro, piso cimentado, telas divisórias de arame liso entre os boxes e cortinas em torno do galpão para controle da temperatura e das correntes de ar. Cada boxe alojou 24 aves, metade de cada sexo.

As dietas experimentais (Tabelas 1 e 2) foram isonutritivas e formuladas para atender às exigências nutricionais dos animais, durante todo o período experimental, de acordo com as recomendações de Rostagno et al. (2005). Foram testados diferentes aditivos melhoradores de crescimento nas rações iniciais de acordo com as recomendações dos fabricantes: ração controle (sem melhorador de crescimento); ração controle + antibiótico (colistina e bacitracina de zinco); ração controle + probiótico; ração controle + prebiótico; ração controle + probiótico + prebiótico .

As aves foram distribuídas em delineamento em blocos casualizados, com cinco tratamentos e quatro repetições, de modo que a unidade experimental foi composta de 24 aves.

O manejo dos animais foi similar ao recomendado pelo manual de criação da linhagem Ross para a fase de 1 a 21 dias, com as aves recebendo água limpa ad libitum e vacinadas contra as doenças de Marek, newcastle e gumboro. Nos dez primeiros dias, foi acionado sistema convencional de aquecimento e o programa de luz foi contínuo, durante as 24 horas do dia, sendo durante o dia com iluminação natural, e a noite com luz artificial, utilizando-se lâmpadas fluorescentes de 100 watts.

O galpão foi dotado de bebedouros e comedouros infantis, e com o avançar da idade dos animais esses foram substituídos por bebedouros pendulares e comedouros tubulares. Cada boxe foi revestido com cama de palha de arroz, com espessura aproximada de $5 \mathrm{~cm}$, durante todo o período experimental, com a finalidade de oferecer maior conforto aos animais. Na tentativa de promover um desafio sanitário, foi misturada à cama nova parte de uma cama já utilizada em outro galpão com frangos de corte com 42 dias de idade, na proporção de $1 \mathrm{~kg} / \mathrm{m}^{2}$.

O monitoramento da temperatura e da umidade do galpão foi realizado por meio de termo-higrômetro, colocado à altura intermediária, em relação aos boxes. As leituras da temperatura e da umidade relativa foram realizadas duas vezes ao dia, às $9 \mathrm{~h} 30 \mathrm{~min}$ e às $16 \mathrm{~h}$. Após os dez primeiros dias de idade das aves, os ventiladores foram acionados nos períodos mais quentes do dia, com a finalidade de diminuir o estresse calórico.

Foram avaliadas as variáveis, consumo de ração (CR), ganho de peso (GP) e conversão alimentar (CA), no período de 1 a 21 dias de idade. Para determinação do consumo de ração e do ganho de peso as aves foram pesadas no início e no final do experimento. $O$ consumo de ração foi calculado 
Tabela 1 - Composição centesimal das rações experimentais na fase pré-inicial ( 1 a 7 dias de idade)

\begin{tabular}{|c|c|c|c|c|c|}
\hline \multirow[t]{2}{*}{ Ingrediente $(\mathrm{kg})$} & \multicolumn{5}{|c|}{ Tratamento } \\
\hline & Controle & Antibiótico & Probiótico & Prebiótico & Probiótico + Prebiótico \\
\hline Milho & 55,49 & 55,00 & 55,48 & 55,29 & 55,26 \\
\hline Óleo de soja & 2,33 & 2,50 & 2,33 & 2,40 & 2,41 \\
\hline Fosfato bicálcico & 1,92 & 1,92 & 1,92 & 1,92 & 1,92 \\
\hline Calcário calcítico & 0,93 & 0,93 & 0,93 & 0,93 & 0,93 \\
\hline DL-metionina & 0,18 & 0,18 & 0,18 & 0,18 & 0,18 \\
\hline Suplemento mineral ${ }^{1}$ & 0,05 & 0,05 & 0,05 & 0,05 & 0,05 \\
\hline Suplemento vitamínico ${ }^{2}$ & 0,05 & 0,05 & 0,05 & 0,05 & 0,05 \\
\hline Nicarbazina $^{3}$ & 0,01 & 0,01 & 0,01 & 0,01 & 0,01 \\
\hline Coban ${ }^{3}$ & 0,02 & 0,02 & 0,02 & 0,02 & 0,02 \\
\hline Colistin 4 & - & 0,04 & - & - & - \\
\hline \multicolumn{6}{|l|}{ Composição nutricional calculada ${ }^{8}$} \\
\hline Energia metabolizável (kcal/kg) & $2.950,00$ & $2.950,30$ & $2.950,00$ & $2.950,30$ & $2.950,30$ \\
\hline Proteína bruta $(\%)$ & 22,00 & 22,00 & 22,00 & 22,00 & 22,00 \\
\hline Cálcio (\%) & 0,94 & 0,94 & 0,94 & 0,94 & 0,94 \\
\hline Fósforo disponível (\%) & 0,47 & 0,47 & 0,47 & 0,47 & 0,47 \\
\hline Fibra bruta $(\%)$ & 3,04 & 3,04 & 3,04 & 3,04 & 3,04 \\
\hline Metionina total (\%) & 0,52 & 0,52 & 0,52 & 0,52 & 0,52 \\
\hline Lisina total $(\%)$ & 1,34 & 1,33 & 1,33 & 1,33 & 1,33 \\
\hline \multicolumn{6}{|c|}{ 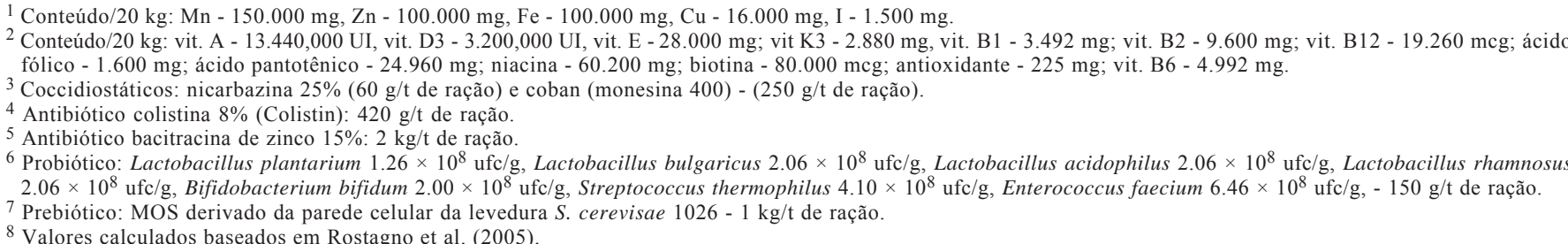 } \\
\hline
\end{tabular}

pela diferença entre a quantidade fornecida e as sobras das rações experimentais. A partir da razão dos dados de consumo de ração pelo ganho de peso, a conversão alimentar foi calculada para o período experimental.

Para a avaliação da histomorfometria do intestino delgado aos 21 dias de idade, foram utilizadas duas aves por boxe, capturadas fundamentando-se no peso médio da parcela, totalizando oito aves por tratamento. Os segmentos do intestino (duodeno, jejuno e íleo) foram abertos pela região mesentérica e fragmentos de aproximadamente 2,0 cm de comprimento foram cuidadosamente coletados, lavados em água destilada, estendidos pela túnica serosa e fixados em solução de Bouin $(150 \mathrm{~mL}$ de solução concentrada de ácido pícrico, $50 \mathrm{~mL}$ de formol comercial $40 \%$ e $10 \mathrm{~mL}$ de ácido acético glacial) por 24 horas. Após esse período, foram submetidos a várias lavagens com álcool 70\% e mantidos nesta solução até a confecção das lâminas. Posteriormente, as amostras foram desidratadas em soluções crescentes de álcool, diafanizadas em xilol e incluídas em parafina e cortadas a $5 \mu \mathrm{m}$ (Prophet et al., 1992).
Foram preparadas três lâminas por animal e em cada lâmina colocados quatro cortes semisseriados, sendo que entre um corte e o subseqüente foram desprezados 12 cortes. As secções foram coradas com hematoxilina-eosina. As análises morfométricas dos cortes histológicos do intestino delgado das aves foram realizadas em analisador de imagem Leica Qwin do Setor de Patologia Animal do CCA-UFPI. Foram selecionados e medidos os comprimentos em linha reta, de acordo com a unidade adotada $(\mu \mathrm{m}), 30$ vilosidades e 30 criptas, bem orientadas, de cada região intestinal, por animal. As medidas de altura de vilosidades foram tomadas a partir da base superior da cripta até o ápice da vilosidade e as criptas foram medidas entre as vilosidades da base inferior até a base superior da cripta (Fukayama et al., 2005; Lopes et al., 2005; Freitas et al., 2007).

Os dados coletados foram submetidos à análise da variância e aplicou-se o teste Student-Newman-Keuls (SNK) para comparação de médias, de acordo com os procedimentos STATISTICAL ANALYSIS SYSTEM SAS (1996). 
Tabela 2 - Composição centesimal das rações experimentais na fase inicial ( 8 a 21 dias de idade)

\begin{tabular}{|c|c|c|c|c|c|}
\hline \multirow[t]{2}{*}{ Ingrediente $(\mathrm{kg})$} & \multicolumn{5}{|c|}{ Tratamento } \\
\hline & Controle & Antibiótico & Probiótico & Prebiótico & Probiótico + Prebiótico \\
\hline Milho & 59,30 & 59,00 & 59,28 & 59,09 & 59,07 \\
\hline Farelo de soja & 35,06 & 35,12 & 35,07 & 35,10 & 35,10 \\
\hline Óleo de soja & 2,32 & 2,42 & 2,32 & 2,39 & 2,39 \\
\hline Fosfato bicálcico & 1,79 & 1,80 & 1,79 & 1,79 & 1,79 \\
\hline Calcário calcítico & 0,89 & 0,88 & 0,89 & 0,89 & 0,89 \\
\hline Sal & 0,30 & 0,30 & 0,30 & 0,30 & 0,30 \\
\hline L-lisina & 0,03 & 0,03 & 0,03 & 0,03 & 0,032 \\
\hline DL-metionina & 0,12 & 0,12 & 0,12 & 0,12 & 0,12 \\
\hline Suplemento mineral ${ }^{1}$ & 0,05 & 0,05 & 0,05 & 0,05 & 0,05 \\
\hline Suplemento vitamínico ${ }^{2}$ & 0,05 & 0,05 & 0,05 & 0,05 & 0,05 \\
\hline Nicarbazina ${ }^{3}$ & 0,01 & 0,01 & 0,01 & 0,01 & 0,01 \\
\hline Coban ${ }^{3}$ & 0,02 & 0,02 & 0,02 & 0,02 & 0,02 \\
\hline Colistin $^{4}$ & - & 0,04 & - & - & - \\
\hline Bacitracina de zinco ${ }^{5}$ & - & 0,10 & - & - & - \\
\hline Colina & 0,04 & 0,04 & 0,04 & 0,04 & 0,04 \\
\hline Probiótico 6 & - & - & 0,01 & - & 0,01 \\
\hline Prebiótico $^{7}$ & - & - & - & 0,10 & 0,10 \\
\hline \multicolumn{6}{|l|}{ Composição nutricional calculada ${ }^{8}$} \\
\hline Energia metabolizável (kcal/kg) & $3.000,00$ & $3.000,00$ & $3.000,10$ & $3.000,00$ & $3.000,00$ \\
\hline Proteína bruta $(\%)$ & 20,80 & 20,80 & 20,80 & 20,80 & 20,80 \\
\hline Cálcio (\%) & 0,88 & 0,88 & 0,88 & 0,88 & 0,88 \\
\hline Fósforo disponível (\%) & 0,44 & 0,44 & 0,44 & 0,44 & 0,44 \\
\hline Fibra bruta $(\%)$ & 2,92 & 2,92 & 2,92 & 2,92 & 2,92 \\
\hline Metionina total $(\%)$ & 0,45 & 0,45 & 0,45 & 0,45 & 0,45 \\
\hline Lisina total $(\%)$ & 1,15 & 1,15 & 1,15 & 1,15 & 1,15 \\
\hline \multicolumn{6}{|c|}{ 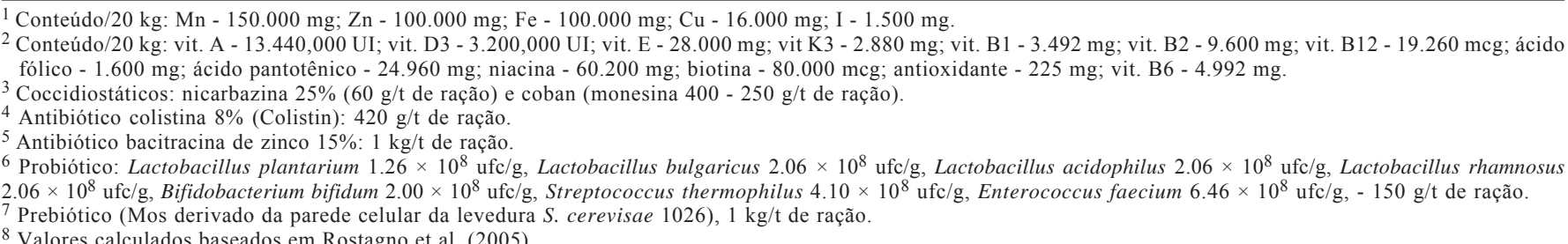 } \\
\hline
\end{tabular}

\section{Resultados e Discussão}

As médias e desvio-padrão da temperatura e umidade relativa do ar foram, respectivamente, de $30,87 \pm 1,98^{\circ} \mathrm{C}$ e $57,48 \pm 5,00 \%$, durante a primeira semana, $30,58 \pm 2,00^{\circ} \mathrm{Ce}$ $57,27 \pm 5,27 \%$, na segunda semana e $30,18 \pm 1,99^{\circ} \mathrm{C}$ e $56,87 \pm 5,48 \%$, na terceira semana do experimento.

Os diferentes melhoradores de crescimento (antibióticos, probiótico, prebiótico e probiótico+ prebiótico) não interferiram $(\mathrm{P}>0,05)$ nas variáveis, consumo de ração $(\mathrm{g})$, ganho de peso (g) e conversão alimentar (g/g) (Tabela 3). As rações com os melhoradores de desempenho não promoveram resultados diferentes daqueles obtidos com a ração controle $(\mathrm{P}>0,05)$ (Tabela 3$)$.

Nesta pesquisa, embora tenha sido induzido um desafio (parte da cama foi reutilizada) no galpão experimental, não houve efeito dos melhoradores de crescimento, esse resultado, provavelmente, está relacionado ao baixo desafio que pode ter sido insuficiente para comprometer o desempenho e histomorfometria intestinal das aves, devido a proporção de cama reutilizada.
Os achados desta pesquisa confirmam os observados por Vargas Júnior et al. (2000), que não encontraram diferenças significativas entre aves submetidas a dietas sem antibióticos, com antibióticos, prebióticos, probióticos e a combinação de prebióticos e probióticos no período de 1 a 21 dias de idade, e atribuíram esse resultado ao baixo desafio de campo em que o experimento foi realizado.

Entretanto, Maiorka et al. (2001) testaram dietas sem aditivo; com antibiótico: Olaquindox e Nitrovin; com prebiótico contendo $0,2 \%$ de parede celular da levedura S. cerevisae; com probiótico à base de Bacillus e com simbiótico e verificaram diferença estatística apenas para conversão alimentar, com o pior valor observado para tratamento controle e o melhor para o tratamento contendo probiótico.

Os resultados para ganho de peso e consumo de ração observado para frangos de corte alimentadas com ração contendo o probiótico protexin contrariam os achados de Loddi et al. (2000), que observaram em aves sob suplementação com o probiótico (Enterococcus faecium cernelle 68) menor ganho de peso e consumo de ração no 
Tabela 3 - Desempenho de frangos de corte alimentados com rações contendo diferentes aditivos melhoradores de crescimento no período de 1 a 21 dias de idade

\begin{tabular}{|c|c|c|c|c|c|c|}
\hline \multirow[t]{2}{*}{ Variável } & \multicolumn{5}{|c|}{ Tratamento } & \multirow[t]{2}{*}{ CV (\%) } \\
\hline & Controle & Antibiótico & Probiótico & Prebiótico & Probiótico + Prebiótico & \\
\hline Consumo de ração (g) & 1119,0 & 1115,7 & 1129,0 & 1141,5 & 1067,2 & 6,31 \\
\hline Ganho de peso (g) & 774,3 & 824,0 & 813,7 & 781,7 & 820,2 & 2,96 \\
\hline Conversão alimentar (g/g) & 1,440 & 1,360 & 1,390 & 1,460 & 1,300 & 8,31 \\
\hline
\end{tabular}

Não houve diferença $(\mathrm{P}>0,05)$ entre tratamentos pelo teste $\mathrm{SNK}$.

período de 1 a 21 dias de idade. Os resultados dessas pesquisas podem ser justificados pelo relato de Jin et al. (1997) e Tournut (1998) de que a eficácia dos probióticos é estritamente dependente de fatores, como quantidade e características das cepas dos microorganismos utilizados na elaboração do aditivo alimentar.

Dionizio et al. (2002) testaram quatro tipos de prebiótico ( $0,9 \%$ de frutooligossacarídeos (FOS); $0,5 \%$ de lactose; $0,05 \%$ de manose; $2,0 \%$ de sacarose) em substituição ao antibiótico (avilamicina $10 \mathrm{ppm}$ ) e verificaram que os prebióticos não influenciaram o consumo de ração, o ganho de peso e a conversão alimentar dos frangos até os 21 dias de idade.

Os valores de ganho de peso médio obtido nesta pesquisa estão de acordo com os encontrados por Corrêa et al. (2003), que testando o Calsporin 10 (probiótico que apresenta como ingrediente ativo esporos de Bacillus subtilis); Estibion aves (poliprobiótico constituído de cepas de Lactobasillus acidophilus, Lactobacillus casei, Estreptococcus salivarium, Estreptococcus faecium, Bacillus subtilis, Bacillus toyoi, Sacharomices cerevisae) e bacitracina de zinco, verificaram que os diferentes tratamentos não influenciaram estatisticamente $(\mathrm{P}>0,05)$ no ganho de peso, sendo observado valores numéricos muito próximos entre eles. Entretanto, os referidos autores encontraram diferença estatística significativa $(\mathrm{P}<0,05)$ para consumo de ração e conversão alimentar, sendo o menor consumo de ração e a melhor conversão alimentar obtidos pelas aves submetidas ao poliprobiótico Estibion aves.

Kalavathy et al. (2003) afirmaram que bactérias do gênero Lactobacillus, adicionadas à ração, aumentaram o ganho de peso e melhoraram a conversão alimentar dos frangos. Albino et al. (2006), ao testarem três tipos de aditivos: um promotor de crescimento (avilamicina) e dois prebióticos (mananoligossacarídeos) com diferentes concentrações de leveduras no período de 1 a 21 dias de idade, verificaram que a adição de avilamicina à ração basal melhorou o ganho de peso, sem afetar o consumo de ração e a conversão alimentar, indicando que o desafio sanitário oferecido pela utilização de cama reutilizada de outro lote, permitiu a manifestação da resposta.
Os resultados das pesquisas científicas utilizando diferentes melhoradores de crescimento como os antibióticos, probióticos, prebióticos e simbióticos, são bastante conflitantes. Tais contradições podem ser justificadas pelo fato dos trabalhos serem realizados utilizando-se diferentes antibióticos e em diferentes concentrações, bem como probióticos com diferentes composições de microorganismos e, mesmo aqueles pertencentes à mesma espécie podem ter diferentes cepas, desta forma a eficácia dos produtos testados é estritamente dependente da quantidade e características das cepas do microorganismo utilizado na elaboração do aditivo alimentar.

Entretanto, apesar dos resultados contraditórios, os probióticos, prebióticos e simbióticos, por serem produtos inovadores, naturais, não tóxicos e que não induzem resistência, devem ser mais pesquisados, pois certamente serão substitutos alternativos dos antibióticos nas rações de frangos de corte. Esse fato justifica-se pelas constantes proibições pelos órgãos oficiais de saúde pública (Halphide, 2003), que têm se manifestados contra a utilização dos antibióticos em rações, seguindo a tendência mundial e obedecendo as normas internacionais para o banimento completo desses promotores de crescimento na nutrição animal.

Os diferentes melhoradores de crescimento estudados interferiram $(\mathrm{P}<0,05)$, apenas sobre a altura de vilo do duodeno, sendo que não houve diferença $(\mathrm{P}>0,05)$ entre tratamentos para os segmentos do jejuno e íleo (Tabela 4). Também não houve diferença $(\mathrm{P}>0,05)$ sobre a profundidade de cripta e perímetro de vilo do duodeno, jejuno e íleo. As aves que ingeriram as rações contendo prebióticos apresentaram o menor valor da altura do vilo no duodeno $(\mathrm{P}<0,05)$ (Tabela 4).

Os resultados, com relação à profundidade de cripta, tanto para o duodeno, como para o jeuno e íleo, estão em consonância com os observados por Pelicano et al. (2003), que ao estudarem diversos probióticos, constataram que não houve diferença significativa entre as dietas com probióticos e a controle. Entretanto, para a altura do vilo e perímetro do vilo no duodeno, os autores observaram 
Tabela 4 - Histomorfometria dos segmentos do intestino delgado de frangos de corte alimentados com rações contendo diferentes aditivos melhoradores de crescimento no período de 1 a 21 dias de idade

\begin{tabular}{|c|c|c|c|c|c|c|}
\hline \multirow[t]{2}{*}{ Variável } & \multicolumn{5}{|c|}{ Tratamento } & \multirow[t]{2}{*}{ CV (\%) } \\
\hline & Controle & Antibióticos & Probiótico & Prebiótico & Probiótico + Prebiótico & \\
\hline & & & Duodeno $(\mu \mathrm{m})$ & & & \\
\hline Profundade cripta & 170,56 & 183,63 & 179,22 & 168,34 & 173,68 & 9,48 \\
\hline \multirow[t]{2}{*}{ Perímetro vilo } & 2615,1 & 2586,3 & 2395,4 & 2261,9 & 2553,9 & 8,43 \\
\hline & & & Jejuno $(\mu \mathrm{m})$ & & & \\
\hline \multirow[t]{2}{*}{ Perímetro vilo } & 2438,4 & 2658,2 & 2546,1 & 2398,2 & 2483,3 & 8,15 \\
\hline & & & Íleo $(\mu \mathrm{m})$ & & & \\
\hline Altura vilo & 726,90 & 805,82 & 840,68 & 848,84 & 749,75 & 14,92 \\
\hline Profundade cripta & 125,16 & 124,46 & 122,70 & 125,68 & 125,96 & 1,36 \\
\hline Perimetro vilo & 2302,0 & 1775,4 & 2038,6 & 2243,0 & 2261,6 & 29,63 \\
\hline
\end{tabular}

Médias seguidas por letras diferentes na mesma linha diferem $(\mathrm{P}<0,05)$ pelo teste SNK

que os probióticos apresentaram maior valor em relação à dieta controle, não havendo diferença para o jejuno e íleo.

Estes resultados estão de acordo com os dados de desempenho, para os quais também não se verificou diferença $(\mathrm{P}>0,05)$ entre os tratamentos testados. Apesar de a altura de vilo do duodeno ter sido afetada $(\mathrm{P}<0,05)$, esse resultado também não foi suficiente para interferir sobre o desempenho dos frangos. Segundo Freitas et al. (2007), a maior altura das vilosidades está relacionada aos resultados de desempenho, em que as aves apresentam maior ganho de peso e melhor conversão alimentar, fato este relacionado com a integridade da mucosa intestinal e processo metabólico, que confere a característica de quanto maior o tamanho dos vilos, maior é a capacidade de digestão e absorção de nutrientes, em função da maior área de contato e efetividade enzimática no nível de mucosa e lúmen intestinal.

\section{Conclusões}

O uso de probiótico, prebiótico, probiótico + prebiótico e antibiótico, em rações para frango de corte no período de 1 a 21 dias de idade, em condições de baixo desafio sanitário, não interfere no desempenho e nas características histomorfométricas dos segmentos do intestino delgado.

\section{Referências}

ASSOCIAÇÃO BRASILEIRA DOS PRODUTORES E EXPORTADORES DE FRANGOS - ABEF. Produção brasileira de carne de frango 2007 (ton). Disponível em: <http:// www.abef.com.br/Estatisticas/MercadoInterno/Atual.php $>$. Acesso em: 1 jul. 2009.
ALBINO, L.F.T.; FERES, F.A.; DIONIZIO, M.H. et al. Uso de prebióticos à base de mananoligossacarídeo em rações para frangos de corte. Revista Brasileira de Zootecnia, v.35, n.3, p.742-749, 2006.

ARAÚJO, J.A.; SILVA, J.H.V.; AMÂNCIO, A.L.L. et al. Uso de aditivos na alimentação de aves. Acta Veterinaria Brasílica, v.1, n.3, p.69-77, 2007.

CORRÊA, G.S.S.; GOMES, A.V.C.; CORRÊA, A.B. et. al. Efeito de antibiótico e probióticos sobre o desempenho e rendimento de carcaça de frangos de corte. Arquivo Brasileiro de Medicina Veterinária e Zootecnia, v.55, n.4, p.467-473, 2003.

DIONIZIO, M.A.; BERTECHINI, A.G.; KANJI KATO, R. et. al. Prebióticos como promotores de crescimento para frangos de corte - Desempenho e rendimento de carcaça. Ciência Agrotécnica, Edição Especial, p.1580-1587, 2002.

EDENS, F.W. An alternative for antibiotics use in poultry: Brazilian Journal of Poultry Science, v.5, n.2, p.75-97, 2003.

FREITAS, R.T.F.; SANTOS, E.C.; TEIXEIRA, A.S. et al. Avaliação de aditivos beneficiadores de crescimento sobre desempenho e morfometria intestinal de frangos de corte na fase inicial. Disponível em: <http://www.fpsols.com/pdf_create_convert.html $>$. Acesso em: 15 fev. 2007.

FUKAYAMA, E.H.; BERTECHINI, A.G.; GERALDO, A. et al. Extrato de orégano como aditivo em rações para frangos de corte. Revista Brasileira de Zootecnia. v.34, n.6, p.2316-2326, 2005 (supl.).

HALPHIDE, B. Role of probiotics in animal nutricion and their link to the demands of European consumers. In: ROLE OF THE EUROPEAN PROBIOTIC ASSOCIATION, 2003. Proceedings... Needertlands, 2003. p.3-4.

JIN, L.Z.; HO, Y.W.; ABDULLAH, N. et al. Probiotics in poultry: modes of action. World's Poultry Science, v. 53, p.351-368, 1997.

KALAVATHY, R.; ABDULLAH, N.; JALALUDIN, S. et al. Effects of Lactobacillus cultures on growth performance, abdominal fat deposition, serum lipids and weight of organs of broiler chickens. British Poultry Science, v.44, n.1, p.139-144, 2003.

LODDI, M.M.; GONZALES, E.; TAKITA, T.S. et. al. Uso de probiótico e antibiótico sobre o desempenho, o rendimento e a qualidade de carcaça de frangos de corte. Revista Brasileira de Zootecnia, v.29, n.4, p.1124-1131, 2000.

LOPES, E. L; JUNQUEIRA, O.M.; ARAÚJO, L.F. et al. Fontes de lactose, níveis de lisina dietéticos e peso dos leitões ao desmame. Revista Brasileira de Zootecnia, v.34, n.6, p.2340-2347, 2005 (supl.). 
MAIORKA, A.; SANTIN, E.; SUGETA, S.M. et. al. Utilização de prebióticos, probióticos ou simbióticos em dietas para frangos. Revista Brasileira de Ciência Avícola, v.3, n.1, p.75-82, 2001.

PELICANO, E.R.L.; SOUZA, P.A.; SOUZA, H.B.A. et al. Morfometria e ultra-estrutura da mucosa intestinal de frangos de corte alimentados com dietas contendo diferentes probióticos. Revista Portuguesa de Ciências Agrárias, v.98, n.547, p.125-134, 2003.

PROPHET, E.M.; MILLIS, B.; ARRINGTON, J.B. et al. Laboratory methods in histotechnology. Washington: America Registry of Pathology, 1992. 275p.

ROSTAGNO, H.S.; ALBINO, L.F.T.; DONZELE, J.L. et al. Tabelas brasileiras para aves e suínos: composição de alimentos e exigências nutricionais. 2.ed. Viçosa, MG: UFV, Departamento de Zootecnia, 2005. 186p.

SHANE, S.M. Mannan oligosaccharides in poultry nutrition: mechanisms and benefi ts. In: ALLTECH'S ANNUAL SYMPOSIUM, 2001, Lexington. Proceedings... Lexington, USA, 2000. p.65-77.

STATISTICAL ANALYSIS SYSTEM - SAS/STAT. User's guide, version 6.11. 4.ed., v.2. Cary: SAS Institute Inc., 1996. 842p. TOURNUT, J.R. Probiotcs. In: REUNIÃO ANUAL DA SOCIEDADE BRASILEIRA DE ZOOTECNIA, 35., 1998, Botucatu. Anais... Botucatu: SBZ, 1998. p.179-199.

VARGAS JÚNIOR, J.G.; TOLEDO, R.S.; ALBINO, L.F.T. et al. Uso de prebióticos em rações de frangos de corte. Revista Brasileira de Ciência Avícola, sup1.2, p.31, 2000. 